\title{
AN ATTEMPT TO IDENTIFY PROPER TEACHING STRATEGIES FOR ROMANIAN BUSINESS UNIVERSITIES
}

\author{
Alexandra Ileana Mutiu ${ }^{I}$
}

\begin{abstract}
The aim of our paper derives from the necessity of adopting teaching strategies that fit better with the students' professional skills. The scope of our paper is to investigate those teaching strategies that can be adopted in Romania in order to help students to gain more professional skills. We identified most recommended teaching strategies applied worldwide. Then, based on constraints identified at Romanian university level, we filtered the teaching strategies in order to find those that can be applied successfully in Romania. We found that intergroup discussion/class debate, teaching stories, teaching using PPT, games, problem based learning, lecture \& discussion, JIT teaching and case studies are strategies that can be applied successfully in our business universities.
\end{abstract}

Key words: teaching strategies, constraints in teaching, international education standards

JEL codes: $M 49$

\section{Introduction}

The necessity of embracing new ways of learning arises from the adoption of International Educational Standards issued by IAESB. IES provides a uniform general global framework for education; they promote convergence in the application of technical and practice standards, contributing to the cooperation of accounting practitioners, university teachers, representatives of the business community, and the public. In this sense, IES stipulate a certain level of required professional knowledge, professional skills, values, ethics and professional attitudes, developing a continuing education approach over the whole duration of life.

The aim of our paper derives from the necessity of adopting teaching methods that fit better with the professional skills students have to become familiar with. Therefore, the scope of our paper is to investigate those teaching strategies that can be adopted in Romania in order to help students to gain more and more professional skills.

The novelty of this paper relies on the fact that teaching strategies in Romanian business universities is not a subject for research until these days.

The paper is developed further in four parts: literature review, methodology, which describes the path we followed and methods we applied in the research, results, and conclusions.

\section{Literature review}

The general IES framework defines the objectives and functioning procedures of EDCOM (IFAC Technical Committee on Control Education), the aim, the area of applicability of International Education Standards, as well as the modalities in which standards can be adopted and applied. strategies:

Regarding International Education Standards (IES 1-7) these include two educational

\footnotetext{
${ }^{1}$ Babes-Bolyai University, Faculty of Economics and Business Administration, Cluj Napoca, Romania, e-mail: alexandra13mutiu@yahoo.com
} 
- the first is related to the stage of prequalification of a professional accountant (IES 16), starting with the university stage and continuing with the training stage required for obtaining the quality of expert accountant or licensed accountant, and

- the second is focused on the continuing professional training of professional accountants, the concept of continuing education throughout the whole active life in the profession being introduced by IES 7 .

Out of these, three standards are related directly with the learning process in universities: IES 2 - Content of Professional Accounting Education Programs, IES 3 - Professional Skills, and IES 4 - Professional Values, Ethics and Attitudes. IES 2 establishes the knowledge and competences required for the work of a professional accountant, i.e. accounting, financing and related knowledge, organizational and business knowledge, along with knowledge and competences in IT, a professional diploma or qualification, as well as at least two years of university studies, day courses. IES 3 - Professional Skills - includes a series of required professional skills: intellectual, technical and functional, personal, interpersonal and communication skills, organizational and business management skills, and emphasizes that general education assists in developing these skills.

IES 4 - Professional Values, Ethics and Attitudes - establishes the required professional values, ethics and attitudes, the minimum study areas, recognizing that the different approaches will reflect the specific cultural and national environment.

Romanian research papers on accounting education shows Romanian universities are doing efforts to adapt their accounting curricula with the IESs. Diaconu (2008) presents the cohesion with IESs in terms of percentages as follows:

\begin{tabular}{|l|c|}
\hline \multicolumn{1}{|c|}{ Universities } & The cohesion with IESs (\%) \\
\hline Babes Bolyai University, Cluj Napoca & 83 \\
\hline Academy of Economics Study Bucharest & 78 \\
\hline Transilvania University Brasov & 65 \\
\hline Romano-American University Bucharest & 57 \\
\hline
\end{tabular}

But Diaconu's work was focused on analyzing the international benchmark versus the stage of the universities by using as single criterion IES 2 . His research didn't touch the teaching methods as vehicle to provide students the tools for self-directed learning.

\section{Research methodology}

In order to investigate those teaching strategies that can be applied in our environment, we started our investigation by following the steps as described above:

Step 1 was about searching in the trade literature the most recommended teaching strategies. Using ANELIS database, we investigated article published after year 2000, using proper key words, like: teaching classes, teaching class, strategy classes, strategy/strategies large classes, teaching business, and teaching accounting.

In step 2 we analyzed the papers found by looking the domain they were applied in. Also, we analyzed if the strategies recommended were empirically tested or not. We believe that if a strategy was proved to be good, this means it is efficient. In the end, we tried to make a ranking of the most recommended strategies. Mainly, this step was about identifying the most popular teaching strategies recommended today

In step 3 we investigated the representative factors that influence the teaching process and we identified constraints which restrict the number of possible strategies to be applied.

Then, in step 4, using the constraints mentioned, we filtered the teaching strategies in order to find the strategies that can be applied successfully in Romania. 


\section{Results}

Our research brought into light many papers that have as central focus teaching strategies. Our wish was to identify the strategies that are most recommended and then to extract those that can avoid the constraints that exist in our environment.

We investigated a total of 54 papers that recommend strategies for different domains, or some of them are not even focused on one. Therefore, their structure on domains is:

- 18 papers present strategies in general and they don't speak about a certain domain where they can be applied in;

- 18 papers discuss strategies applied in business area, like accounting, management, economics, and micro economy;

- 13 papers are focused on strategies used in social and political sciences;

- 5 papers present strategies in different areas, like Earth science, biochemistry, physics, history, and math.

Out of the total, 30 papers empirically tested the strategies presented while the rest don't have any statistical evidence.

A classification of the teaching strategies based on how often they were recommended in the papers is presented below:

Classification of the teaching strategies identified

\begin{tabular}{|c|l|c|}
\hline No. & \multicolumn{1}{|c|}{ Teaching strategies } & $\begin{array}{c}\text { No of papers that } \\
\text { recommend it }\end{array}$ \\
\hline 1. & Using online facilities & 14 \\
\hline 2. & Clickers & 9 \\
\hline 3. & Team work/ projects & 8 \\
\hline 4. & JIT teaching & 4 \\
\hline 5. & Intergroup discussion / class debate & 4 \\
\hline 6. & Quizzes & 3 \\
\hline 7. & Problem based learning & 3 \\
\hline 8. & Lecture \& discussion & 3 \\
\hline 9. & Case studies / Connection to the real world & 3 \\
\hline 10. & Work outside the classroom & 2 \\
\hline 11. & Teach stories & 2 \\
\hline 12. & Coaching students & 2 \\
\hline 13. & Games and simulations & 1 \\
\hline 14. & Feedback offered to students & 1 \\
\hline 15. & PPT & 1 \\
\hline 16. & Written assignments & \\
\hline
\end{tabular}

It can be seen from the table above that most recommended strategies are based on online facilities. 14 papers support the idea that lecture notes online, streaming videos of lectures, multimedia including digital video, Web resources including hypertext, enhanced hypermedia, emails, discussion forums, and blogs are widely used in education area.

In the same spirit, clickers held the second place in terms of teachers' preferences in regard to teaching strategies. Multiple-choice questioning of the students using Personal Response System technologies, as clickers, (Elliott, 2003) are considered to be a very useful tool applied in learning. Students find clickers very beneficial (Salemi, 2008).

Team work or team projects represent a very useful strategy in developing students' abilities to communicate and interact in different situations and places.

At a larger distance, Just-in-time teaching, followed by quizzes, problem based learning, lecture combined with discussion, and teaching case method are recommended strongly. Among most preferred also by teachers and students, these techniques proved to be effective even in large classes (Carpenter, 2006) 
Also, intergroup discussion and class debate (based on cases and problems, questions) is another way to get students involved in the learning process.

Offering feedback, coaching them represent a way of learning also.

Among ones of the most fascinating strategies could be considered teaching games and teaching stories. A good story can illustrate management principles such as decision-making, leadership, group dynamics, power and politics in a way that captures students' attention and enhances memory (Harbin, 2010). The authors suggest storytelling is not only an effective teaching tool, but is an essential leadership skill that should be taught in our business schools (Harbin, 2010).

But not all of the teaching strategies presented above can be applied in the Romanian business universities. This relies heavily on the factors that influence the decision of using one or another strategy. Grigoroi (2011) identifies these factors as being:

- Content of the learning

- Class's particularity (referring to number of students, their expectations, learning styles)

- Available time for working with students

- Available resources

At a deeper analysis we noticed that the first criterion: content of the learning does not represent a restrictive factor in regard with other countries or universities. As long as the Romanian universities' curriculum is harmonized with the international education standards, the content of learning doesn't exist like a particularity of our country.

The second criterion is a very complex one. In many Romanian universities, the numbers of students enrolled in class exceed 100 students. Their expectations can be extremely diversified: some of them don't attend classes since they have a job; some of them come to classes just for being there and some really want to learn. On the other hand, we don't measure students' expectations and their learning style. The third factor: available time for working with students is about the standard class time, which is about 2 hours. This is why we believe that this factor is not a real constraint. But the one that really concerns is the last factor: available resources, in terms of financial resources available at the university's level and also on students' level.

Using the strategies identified so far in the present paper, we wanted to analyze which of them would fit better in Romanian universities. We did this using the criteria presented above.

\section{Conclusions}

As we mentioned before, the main restriction we have to deal with is the available resource. Lack of financial resources allocated for class activities combined with the poverty of population does not allow us to teach using sophisticated technology like: online facilities and clickers, and simulations.

The rest of the remained strategies could be classified in two groups, with respect to available time for working with students.

Strategies that imply a lot of individual or group feedbacks are: quizzes, team work/ projects, written assignments, work outside the classroom, and coaching students. Considering we have large classes, with more than 70 students, these strategies are very time consuming. Therefore, even if teachers' commitment to the class is very high, these methods are not suitable for large classes.

Strategies that are not build necessary on students' feedback are: intergroup discussion / class debate, teaching stories, teaching using PPT, games, problem based learning, lecture \& discussion, JIT teaching and case studies. Since these don't rely necessarily on giving students feedback, these teaching strategies depend mostly on teachers' willingness to apply them. Some of them are already used in Romanian academic environment, like teaching using PowerPoint presentations, and lectures. But other strategies, like class debate, games and discussion are known as more powerful than the latter mentioned. 
Therefore, we may conclude that intergroup discussion/class debate, teaching stories, games, discussion, JIT teaching and case studies are strategies that should be considered by Romanian business universities to be applied in the classroom.

\section{Acknowledgements}

Authors would like to acknowledge the participants to the Audit and Accounting Convergence 2009 Annual Convention for their helpful comments and suggestions. This work was supported by CNCSIS-UEFISCSU, project number PNII - IDEI 2476/2008, "Study regarding the development process of the Romanian educational accounting system toward a global economic environment".

\section{References}

1. Carpenter J. M., 2006. Effective teaching methods for large classes, Journal of Family \& Consumer Sciences Education, Vol. 24, No. 2, Fall/Winter.

2. Diaconu P., 2008. Directions of the accounting educational curricula in the Romanian universities and the conformity with IES provided by IFAC, AMIS Conference, Bucharest.

3. Elliott C., 2003. Using a Personal Response System in Economics Teaching. International Review of Economics Education, volume 1, issue 1, 80-86

4. Grigoroi L., 2011. Metode avansate, aplicate în predarea contabilității, available on-line at http://siteresources.worldbank.org/EXTCENFINREPREF/Resources/41521171270824012230/6954188-1299453142594/1_grigoroi_metode_avansate_de_predare.pdf, consulted on the $29^{\text {th }}$ of September 2011

5. Harbin J., 2010. Teaching management by telling stories. Academy of Educational Leadership Journal Vol 14. 1: 99-106.

6. Salemi M. K., 2008. Clickenomics: Using a Classroom Response System To Increase Student Engagement In a Large-Enrollment Principles of Economics Course. American Economic Association posts Conference Papers 